Preventive Medicine 31, 396-402 (2000)

doi:10.1006/pmed.2000.0728, available online at http://www.idealibrary.com on IDE $\mathbf{L}^{\circledR}$

\title{
Evaluation of a Population-Based Screening for Type 2 Diabetes: A Community-Based Screening Project in Puli, Taiwan
}

\author{
Hong-J en Chang, M.S., * Hsu-Sung Kuo, Ph.D.,† Tao-Hsin Tung, M.S.,‡ Pesus Chou, Dr.P.H.,‡ \\ and Tony Hsiu-Hsi Chen, Ph.D. $\S^{1}$

\begin{abstract}
*Bureau of National Health Insurance, Department of Health, Taiwan, Republic of China; †Department of Health, Taiwan, Republic of China; ¥Community Medicine Research Center \& Institute of Public Health, College of Medicine, National Yang-Ming University, Taipei, Taiwan, Republic of China; and §Graduate Institute of Epidemiology, College of Public Health, National Taiwan University, Taipei, Taiwan, Republic of China
\end{abstract}

Background. A Markov method incorporating the relationships between prevalence, incidence, and mortality with respect to type 2 diabetes was used to assess a population-based screening for this disease.

Methods. Data from a population-based screening project for residents of Puli, Taiwan, over 30 years of age $(n=1,219)$ were used to estimate the annual incidence of asymptomatic type 2 diabetes, the prevalence to incidence $(P / I)$ ratio, and the hazard rate of death due to type 2 diabetes. These parameters were employed to develop a Markov process to evaluate the effects of early detection of type 2 diabetes on the risk of death from this disease in a simulated population ( $n=10,000)$ receiving biennial, 5-year interval, or no screening.

Results. The estimated annual incidence, average duration from asymptomatic to symptomatic type 2 diabetes ( $P / I$ ratio), and hazard rate for death from this disease were $0.86 \%$ (95\% CI $0.50-1.48)$, 10 years (95\% CI 7.69-14.01), and 1.1\% per year, respectively. This yields an optimal screening interval of 5 years. Simulation of a 5-year interval screening regimen versus no screening yielded a relative risk reduction of $31 \%(95 \% \mathrm{Cl}$ $12-46 \%$ ). A similar value was found for a biennial screening regime.

Concl usions. The results suggest that early detection of type 2 diabetes via a community-based screening project in developing countries with high prevalence is worthwhile. 2000 American Health Foundation and Academic Press Key Words: type 2 diabetes; Markov model.

\footnotetext{
${ }^{1}$ To whom correspondence and reprint requests should be addressed at Graduate Institute of Epidemiology, College of Public Health, National Taiwan University, Room 213, No. 19, Su-Chow, Taipei, Taiwan. Fax: 886-2-23587707.
}

\section{INTRODUCTION}

Type 2 diabetes is one of the major chronic diseases. Most cases are asymptomatic in their early stages and can therefore remain undiagnosed for many years. According to Harris [1], early detection of type 2 diabetes to prevent further progression to symptomatic cases is imperative. Nonetheless, there is a continuing debate as to whether screening for asymptomatic type 2 diabetes is necessary. The opposition to screening for type 2 diabetes is due to the unproven benefit of type 2 diabetes screening on the basis of controlled intervention studies [2,3]. In addition, screening may lead to overdiagnosis, unnecessary treatment, adverse effect, and high cost $[4,5]$. However, two recent review articles by the American Diabetes Association [6] and by Harris et al. [7], respectively, have strongly suggested that there is a need for a screening program to allow early detection of type 2 diabetes because undiagnosed type 2 diabetes may have a long latency (10 years) from its onset to clinical diagnosis. Another study from the CDC Diabetes Cost-Effectiveness Study Group has suggested that opportunistic screening for type 2 diabetes is cost-effective, particularly for young people [8]. Nonetheless, there is a lack of empirical evidence on the efficacy of population-based screening for type 2 diabetes.

I deally, the efficacy of a population-based screening for type 2 diabetes would best beassessed by conducting a randomized trial that compares cumulative mortality or relevant complications in screened and control groups. Such studies are very costly and time-consuming because they require long follow-up periods. Moreover, even if screening for type 2 diabetes is warranted, a series of subsidiary issues will be raised including whom, where, when, and how often to screen. One cannot merely rely on randomized trials to evaluate these 
questions. Thus, development of a less costly and less time-consuming method to evaluate the efficacy of early detection of type 2 diabetes would be of obvious benefit. Assessment of the efficacy of early detection of type 2 diabetes is highly dependent on whether the natural disease progression (Apparently healthy $\rightarrow$ asymptomatic $\rightarrow$ symptomatic $\rightarrow$ death from type 2 diabetes) can be understood and quantified. To our knowledge, few studies have focused on quantifying this relationship.

Elucidation of the relationships between prevalence, incidence, and mortality allows early assessment of the progression of type 2 diabetes (from no disease to death from type 2 diabetes). F or example, the ratio of prevalence to incidence ( $\mathrm{P} / \mathrm{I}$ ratio) often represents the average duration from asymptomatic type 2 diabetes to symptomatic type 2 diabetes as was stated by F reeman and Hutchison [9]. Estimation of this index may be very helpful in determining the optimal interval between screening tests for early detection of type 2 diabetes. In addition, estimating the rate of progression from symptomatic type 2 diabetes to death from type 2 diabetes provides an estimate for the cumulative survival of patients with symptomatic type 2 diabetes.

In this study, we used data from a population-based screening project, estimating the prevalence and incidence of, and mortality from, type 2 diabetes. We also estimate the average duration from asymptomatic to symptomatic type 2 diabetes and the cumulative survival of persons with the disease. Using theseestimates, we applied a Markov process to simulate a randomized controlled trial of screening program with specific interscreening interval, to eval uate the effects of early detection on reducing the rate of death due to type 2 diabetes. The effect of different screening frequencies on the efficacy of early detection was also examined.

\section{METHODS}

\section{Data Resource}

Data used in this study were derived from a population-based screening project conducted in Puli, Taiwan. Details of the study design and execution have been described in elsewhere [10]. In brief, a total of 2,061 subjects, 30 years of age or older, in Puli, Taiwan, were invited to the first screen from J uly 1987 until February 1988. Only 1,152 subjects received blood sugar test and the response rate was approximately 56\% (1,152/2,061). After the first screen, subsequent screenings were conducted in two periods: between J uly 1991 and February 1992 and between J uly 1994 and February 1995. Because this was a nonrandomized service, new subjects could enter into the first screen in any of these three periods. Accordingly, threefixed cohorts were identified according to when subjects attended their first screen. Because few new subjects attended the screen between
J uly 1994 and F ebruary 1995, this cohort was excluded from the analysis.

Among 1,152 attendants in the 1987-1988 cohort, there were 331 subjects in the first screening who did not take the oral glucose tolerance test (OGTT). They were excluded from the analysis. Also excluded were 77 cases who were reported as previously having type 2 diabetes. Sixty-six (8.9\%) subjects of the remaining 744 patients tested had asymptomatic type 2 diabetes. Among the 678 normal subjects, 361 subjects were lost to follow-up. Among 317 attendants in the second screening (1991-1992), only 237 (31.9\%) subjects had complete information on the OGTT. Of these, 10 had newly diagnosed asymptomatic type 2 diabetes. F or the 1991-1992 cohort, there were 1,314 participants; of these, 806 subjects had not completed the OGTT test. Thirty-three subjects reported as previously having type 2 diabetes were excluded. Thirty-nine (8.2\%) of the remainder (475) with complete OGTT information were found to have asymptomatic type 2 diabetes at the time of the first screening. Among the 436 apparently healthy subjects, 215 could not be traced. Thirty-two subjects out of 221 attendants in the second screening (1994-1995) had incomplete OGTT information. Among the 189 (40\%) asymptomatic subjects with complete OGTT information, 3 (1.6\%) were found to have type 2 diabetes. Table 1 shows the analysis for two fixed cohorts.

To ascertain deaths from type 2 diabetes, the above 118 asymptomatic type 2 diabetes patients were linked to the mortality registry in Taiwan until December 1997. Theabove definition of "deaths from type 2 diabetes" refers to deaths specifically related to diabetes $(I C D=250)$ that was coded as the underlying cause of death on the death certificate. One case of asymptomatic type 2 diabetes was excluded from the survival analysis because the date of death was unknown. Among the 117 subjects, there were 8 deaths from type 2 diabetes $(I C D=250), 5$ deaths from cerebrovascular disease $(I C D=430-438)$, 3 deaths from ischemic heart

\section{TABLE 1}

Descriptive Results of Early Detection of Type 2 Diabetes for Two Fixed Cohorts in Puli, Taiwan
J uly 1987-
J uly 1991-
Feb 1988
Feb 1992
Cohort 1
Cohort 2

\section{First screening}

Asymptomatic type 2 diabetes Negative

Total

678

744

39

Second screening

Asymptomatic type 2 diabetes

Negative

Total

10

227

237
436

475

\section{3}

186

189 
disease (ICD $=410-414), 4$ deaths from carcinoma (ICD $=140-208), 4$ deaths from a disease of the digestive system $(I C D=520-579)$, and 4 deaths from others causes.

The Natural History of the Disease and the Markov Model

For the purpose of this study, weassumed thenatural history of type 2 diabetes to be depicted by the process shown in Fig. 1.

The progression rate of $\lambda_{1}, \lambda_{2}$, and $\lambda_{3}$ can bedelineated by a Markov process. $\lambda_{1}$ is the preclinical incidence of asymptomatic disease. $\lambda_{2}$ and $\lambda_{3}$ represent the progression rates from asymptomatic type 2 diabetes to symptomatic type 2 diabetes and from the symptomatic stage to death, respectively.

Type 2 diabetes was defined according to the modified WHO criteria in [8]. Asymptomatic cases were found through a blood sugar screening project targeted at the general population. These cases were free of clinical manifestation when detected. Symptomatic cases were defined by the presence of clinical manifestation.

Details of the linkage between the above natural history and the Markov model were described elsewhere [11].

\section{Estimation of $\lambda_{1}, \lambda_{2}$, and $\lambda_{3}$}

We assumed that in a steady population, the incidence of asymptomatic type 2 diabetes denotes the rate of progression from "apparently healthy" to asymptomatic type 2 diabetes. This rate was estimated from the number of new asymptomatic cases detected at the second screening divided by person years contributed by subjects at risk (Appendix A). The prevalence rate of type 2 diabetes was estimated by the number of cases found at the first screening divided by the number attendant at the first screening. We used the inverse of the $\mathrm{P} / \mathrm{l}$ ratio (the ratio of prevalence to incidence) to estimate the hazard rate of $\lambda_{2}$ as this ratio can be used to estimate an average duration from asymptomatic to symptomatic type 2 diabetes, according to the Rothman prevalence pool concept [12]. The incidence rate I was obtained from the above $\lambda_{1}$. Details of the algebra are presented in Appendix A.
Because we did not observe data on the progression from symptomatic type 2 diabetes to death from this disease, it was difficult to make a direct estimation of $\lambda_{3}$. We used the Walter and Stitt method [13], which estimates the hazard rate of death after adjustment for lead time (the time gained from early detection) to tackle this problem. Following the Walter and Stitt method, $\lambda_{3}$ was estimated on the basis of asymptomatic type 2 diabetes cases only. The first step of this method was to estimate the cumulative survival of asymptomatic type 2 diabetes patients on the basis of the 8 deaths from this disease and 20 deaths from other causes, using the Kaplan-Meier method. Given the above estimate of $\lambda_{2}$ (the parameter related to lead time), $\lambda_{3}$ can be estimated. An illustration of the adjustment of death for lead time is shown in Appendix B.

The estimates of $\lambda_{1}, \lambda_{2}$, and $\lambda_{3}$ allow transition probabilities during time t to be calculated. These transition probabilities can be used to predict the numbers of asymptomatic and symptomatic type 2 diabetes cases and deaths from type 2 diabetes among cohorts participating in specific screening regimens (i.e., a 5-year interscreening interval versus no screening control). The relative efficacy of early detection of type 2 diabetes can thus be simulated.

\section{A Simulation Program for Evaluating the Efficacy of Early Detection in Reducing the Rate of Death from Type 2 Diabetes}

We used a split-stop design [14] to simulate the efficacy of early detection of type 2 diabetes. With this design, a hypothetical population $(n=10,000)$ was randomly assigned to two groups: members of one group participated in a multiyear regimen and those in the other group received no screening (control group). We assumed that the lead time gained from screening is equal to half of the time interval between diagnosis of asymptomatic type 2 diabetes and progression to symptomatic disease (assuming a uniform distribution). Thus, $x$ is equal to half of the $P / /$ ratio estimated above.

Best-case estimates of attendance rate and sensitivity were assumed to be 56 and $88 \%$; these were derived from the above empirical data. The study duration was $\begin{array}{ll}\lambda_{1} & \lambda_{2} \\ \text { Apparently healthy } \rightarrow \text { Asymptomatic Type 2 Diabetes } \rightarrow \text { Symptomatic Type 2 Diabetes }\end{array}$

(State 0)

(State 1)

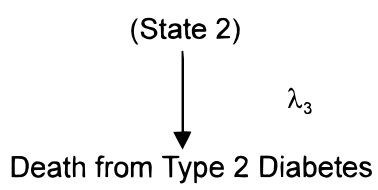

(State 3)

FIG. 1. The natural history of type 2 diabetes. 
10 years and the follow-up after diagnosis of asymptomatic type 2 diabetes cases was also 10 years. Compared to the control group, we assume that asymptomatic cases detected by screening will have good control over glycemic level via a combination of treatment modalities, including diet and exercise only, oral hypoglycemic agents only, insulin only, or both oral hypoglycemic agents and insulin. We also assume that early control of glycemic level can reduce the incidence of microvascular complications in type 2 diabetes and lead to further reduction of deaths from acute complications of diabetes, renal disease deaths, and deaths from cardiovascular disease. At theclose of the study, the control group underwent a single screening for type 2 diabetes. The above transition probabilities were used in the simulation program to calculate the predicted numbers of asymptomatic and symptomatic type 2 diabetes cases and deaths from this disease for a multiyear interval screening regimen and a control group. The relative efficacy of multiyear interval screenings in reducing the incidence of symptomatic type 2 diabetes and death from it could thus be estimated.

\section{RESULTS}

Estimates of Prevalence and Incidence of

Asymptomatic Disease and Hazard Rate for

Progression to Symptomatic Type 2 Diabetes

Table 2 shows estimates of the prevalence of asymptomatic type 2 diabetes in the first screening and the incidence in the second screening. The overall prevalence rate was $8.61 \%(95 \% \mathrm{Cl} 7.04-10.18 \%)$ and the incidence rate of type 2 diabetes was $0.86 \%(95 \% \mathrm{Cl}$ $0.50-1.48 \%$ ) per year. The prevalence rate for those aged 50 years or above was almost four times that for those under 50 years. The incidence rate for subjects aged 50 years or over was approximately three times that of those under 50 years. Theprevalencerateamong women was slightly higher than among men. The incidence rate was the same in men and women.

Table 2 also shows the $\mathrm{P} / \mathrm{I}$ ratio (ratio of prevalence to annual incidence rate) by age and sex. The overall $\mathrm{P} / \mathrm{l}$ ratio was $10.01(8.61 / 0.86 \%)$ years $(95 \% \mathrm{Cl} 7.69$ 14.01). The $\mathrm{P} / \mathrm{l}$ ratios were $7.79(95 \% \mathrm{Cl} 4.89-15.89)$ for subjects below 50 years of age and $10.72(95 \% \mathrm{Cl}$ 7.87-16.24) for those 50 years or above. The corresponding figures for men and women were 8.52 (95\% Cl 5.83$14.61)$ and 11.47 (95\% Cl 8.11-18.66), respectively. When estimates consi dered sex and agesimultaneously, the $\mathrm{P} / \mathrm{l}$ ratios were $7.75(95 \% \mathrm{Cl} 4.15-26.87)$ for men under 50 years of age and $8.93(95 \% \mathrm{Cl} 5.69-18.12)$ for those 50 years or above. The corresponding figures for women were 7.57 (95\% Cl 3.97-26.31) and 11.89 (95\% $\mathrm{Cl}$ 8.01-21.72), respectively.

Application of the Walter and Stitt method to the cumulative 7-year survival of 117 patients with asymptomatic type 2 diabetes yielded an estimated hazard rate of death from type 2 diabetes $\left(\lambda_{3}\right)$ of $1.1 \%$ per year.

\section{Simulated Results for Predicted Numbers of}

Asymptomatic Type 2 Diabetes, Symptomatic

Type 2 Diabetes, and Death from this Disease

Because the $\mathrm{P} / \mathrm{I}$ ratio in this study was estimated to be 10.01 , a 5-year screening (i.e., half the $\mathrm{P} / \mathrm{I}$ ratio) regimen was used in simulations to obtain predicted numbers of asymptomatic cases, symptomatic cases, and deaths from type 2 diabetes in the study and control groups. The results are summarized in Table3. Overall, the relative risk of subjects in the 5-year screening regimen versus those of a control group was 0.69 (95\% $\mathrm{Cl}$ 0.54-0.88). This suggests that a 5-year screening regimen may lead to a $31 \%(95 \% \mathrm{Cl} 12-46 \%)$ reduction in the rate of deaths from type 2 diabetes. Similar results were obtained for groups stratified by age, sex, or both. Table 4 shows simulated results on the efficacy of early detection from a biennial screening regime.

\section{DISCUSSION}

We evaluated the efficacy of early detection of type 2 diabetes with a Markov process, using the relationships between prevalence, annual incidence, and hazard rate based on the cumulative survival of patients with asymptomatic type 2 diabetes adjusted for lead time. This was the first time, to the best of our knowledge, that this relationship and an application of the Markov process in this context has been used to assess the efficacy of early detection of type 2 diabetes. The P/I ratio suggests that a 5-year screening interval may be optimal for early detection of this disease in Taiwan. This 5-year regime was also shown to reduce the risk of death from type 2 diabetes by about 31\%, given a $56 \%$ attendance rate and $88 \%$ sensitivity. Assuming $100 \%$ sensitivity and $100 \%$ attendance rate, one would achieve $51 \%$ reduction of mortality. The implication is that finding diabetes 5 years earlier than without screening can diminish the incidence of microvascular complications. This, in turn, reduces deaths from acute complications or renal disease. The biological plausibility of our finding was consistent with the recent study from the CDC Diabetes Cost-E ffectiveness Study Group which stated that opportunistic screening for type 2 diabetes can significantly reduce the lifetime cumulative incidence of microvascular complications [8].

It should be noted that the described benefit of early detection by screening for type 2 diabetes is contingent upon the premise that, compared to the control group, asymptomatic cases detected by screening must take good control over glycemic level via a combination of treatment modalities, including diet and exercise only, oral hypoglycemic agents only, insulin only, or both oral 
TABLE 2

Prevalence (P), Incidence (I), and P/I Ratio of Type 2 Diabetes by Age and Sex in Puli, Taiwan

\begin{tabular}{|c|c|c|c|c|c|}
\hline Variable & $\begin{array}{l}\text { No. of prevalent } \\
\text { asymptomatic } \\
\text { type } 2 \text { diabetes }\end{array}$ & $\begin{array}{l}\text { Prevalence (\%) } \\
\quad(95 \% \mathrm{Cl})\end{array}$ & $\begin{array}{c}\text { No. of } \\
\text { asymptomatic } \\
\text { type } 2 \text { diabetes }\end{array}$ & $\begin{array}{c}\text { Incidence (\%) } \\
(95 \% \mathrm{Cl})\end{array}$ & $\begin{array}{c}\mathrm{P} / \mathrm{l} \\
(95 \% \mathrm{Cl})\end{array}$ \\
\hline \multicolumn{6}{|l|}{ Age (years) } \\
\hline$<50$ & $\begin{array}{c}24 \\
(642)\end{array}$ & $\begin{array}{c}3.74 \\
(2.27-5.21)\end{array}$ & $\begin{array}{c}4 \\
(231)\end{array}$ & $\begin{array}{c}0.48 \\
(0.18-1.28)\end{array}$ & $\begin{array}{c}7.79 \\
(4.89-15.89)\end{array}$ \\
\hline$\geq 50$ & $\begin{array}{c}81 \\
(577)\end{array}$ & $\begin{array}{c}14.04 \\
(11.21-16.87)\end{array}$ & $\begin{array}{c}9 \\
(195)\end{array}$ & $\begin{array}{c}1.31 \\
(0.68-2.52)\end{array}$ & $\begin{array}{c}10.72 \\
(7.87-16.24)\end{array}$ \\
\hline Total & $\begin{array}{c}105 \\
(1,219)\end{array}$ & $\begin{array}{c}8.61 \\
(7.04-10.18)\end{array}$ & $\begin{array}{c}13 \\
(426)\end{array}$ & $\begin{array}{c}0.86 \\
(0.50-1.48)\end{array}$ & $\begin{array}{c}10.01 \\
(7.69-14.01)\end{array}$ \\
\hline \multicolumn{6}{|c|}{ (1) } \\
\hline Male & $\begin{array}{c}43 \\
(594)\end{array}$ & $\begin{array}{c}7.24 \\
(5.16-9.32)\end{array}$ & $\begin{array}{c}6 \\
(198)\end{array}$ & $\begin{array}{c}0.85 \\
(0.38-1.89)\end{array}$ & $\begin{array}{c}8.52 \\
(5.83-14.61)\end{array}$ \\
\hline Female & $\begin{array}{c}62 \\
(621)\end{array}$ & $\begin{array}{c}9.98 \\
(7.62-12.34)\end{array}$ & $\begin{array}{c}7 \\
(228)\end{array}$ & $\begin{array}{c}0.87 \\
(0.41-1.82)\end{array}$ & $\begin{array}{c}11.47 \\
(8.11-18.66)\end{array}$ \\
\hline Total & $\begin{array}{c}105 \\
(1,215)\end{array}$ & $\begin{array}{c}8.64 \\
(7.06-10.22)\end{array}$ & $\begin{array}{c}13 \\
(426)\end{array}$ & $\begin{array}{c}0.86 \\
(0.50-1.48)\end{array}$ & $\begin{array}{c}10.05 \\
(7.71-14.06)\end{array}$ \\
\hline \multicolumn{6}{|c|}{ Sex $\times$ Age (years) } \\
\hline Male, $<50$ & $\begin{array}{c}13 \\
(294)\end{array}$ & $\begin{array}{c}4.42 \\
(2.07-6.77)\end{array}$ & $\begin{array}{c}2 \\
(98)\end{array}$ & $\begin{array}{c}0.57 \\
(0.14-2.28)\end{array}$ & $\begin{array}{c}7.75 \\
(4.15-26.87)\end{array}$ \\
\hline Male, $\geq 50$ & $\begin{array}{c}30 \\
(300)\end{array}$ & $\begin{array}{c}10.00 \\
(6.61-13.39)\end{array}$ & $\begin{array}{c}4 \\
(100)\end{array}$ & $\begin{array}{c}1.12 \\
(0.04-2.98)\end{array}$ & $\begin{array}{c}8.93 \\
(5.69-18.12)\end{array}$ \\
\hline Female, $<50$ & $\begin{array}{c}11 \\
(346)\end{array}$ & $\begin{array}{c}3.18 \\
(1.33-5.03)\end{array}$ & $\begin{array}{c}2 \\
(133)\end{array}$ & $\begin{array}{c}0.42 \\
(0.01-1.68)\end{array}$ & $\begin{array}{c}7.57 \\
(3.97-26.31)\end{array}$ \\
\hline Female, $\geq 50$ & $\begin{array}{c}51 \\
(275)\end{array}$ & $\begin{array}{c}18.55 \\
(13.96-23.14)\end{array}$ & $\begin{array}{c}5 \\
(95)\end{array}$ & $\begin{array}{c}1.56 \\
(0.06-3.75)\end{array}$ & $\begin{array}{c}11.89 \\
(8.01-21.72)\end{array}$ \\
\hline
\end{tabular}

${ }^{a}$ Four subjects were missing information on sex.

hypoglycemic agents and insulin. If such a commitment cannot be met, early detection of type 2 diabetes is unlikely to gain the benefit, however.

In addition, the application of mass screening for type 2 diabetes may contribute to a positive health effect from being screened and found to be negative for diabetes. The initial screening may also add the benefit of preventing incident diabetes. Several other benefits come from health education, the impact of a positive sense of well-being on overall health, promoting a greater level of social interaction, and more physical activity. A futurestudy may be conducted to investigate such additional benefits.

Since the $P / I$ ratio represents the estimate of the average duration from asymptomatic to symptomatic type 2 diabetes, this ratio reflects how long it would take for type 2 diabetes to progress from the asymptomatic phase to the symptomatic phase: the larger the ratio, the longer the duration. The overall $\mathrm{P} / \mathrm{I}$ ratio estimated in this study shows that the average duration from the asymptomatic to the symptomatic phase is approximately 10.01 years, which is close to the 9- to 12-year estimate reported by Harris et al. [7]. Their estimate was obtained by first regressing the rate of retinopathy with time to obtain a linear regression equation, whereby the average duration of the asymptomatic phase of retinopathy was estimated as being 4- 7 years. Because this estimate did not consider the passage of time before asymptomatic retinopathy, they further estimated the duration from asymptomatic to symptomatic type 2 diabetes to be 9-12 years on the basis of the study by J arrett [15]. Our estimate of this duration was also close to that used in one recent study on the cost-effectiveness of screening for type 2 diabetes [8]. The effectiveness of early diagnosis and treatment via opportunistic screening of type 2 diabetes was demonstrated in that study by using an average of 10.5 years elapsing between onset and clinical diagnosis of type 2 diabetes and assuming that screening reduces the mean prediagnosis interval by 5 years from 10.5 to 5.5 years. If the benefit of early detection of type 2 diabetes via lead time gained is proportional to the efficacy of mortality reduction, the benefit dueto shortening the prediagnosis interval used by the CDC diabetes cost-effectiveness study group [8] is consistent with a 50\% reduction of mortality from the estimates in our study.

From theage-specific $\mathrm{P} / \mathrm{l}$ ratio, wefound that $\mathrm{P} / \mathrm{I}$ ratio increases with age. This may suggest that progression from asymptomatic to symptomatic type 2 diabetes in younger subjects is more rapid than in old subjects. The duration was slightly longer in women than in men, which may at least partially explain why women aged 50 years or over had the greatest benefit in terms of reducing in the rate of deaths from type 2 diabetes. This further implies that the time interval for early detection of type 2 diabetes may vary by age and sex. 
TABLE 3

Simulated Results of the Efficacy of Early Detection of Type 2 Diabetes for 5-Yearly Screening Regime versus the Control Group in a Hypothetical Population $(n=10,000)$ by Sex and Age or Both, Assuming $88 \%$ Sensitivity and $56 \%$ Attendance Rate

\begin{tabular}{|c|c|c|c|}
\hline & \multicolumn{2}{|c|}{$\begin{array}{c}\text { Death from type } 2 \\
\text { diabetes }\end{array}$} & \multirow{2}{*}{$\begin{array}{c}\text { RR screened/ } \\
\text { control } \\
(95 \% \mathrm{Cl})\end{array}$} \\
\hline & Screened & Control & \\
\hline \multicolumn{4}{|l|}{ Age (years) } \\
\hline$<50$ & 61.71 & 87.17 & $0.71(0.51-0.98)$ \\
\hline$\geq 50$ & 154.94 & 231.80 & $0.67(0.55-0.82)$ \\
\hline Total & 106.34 & 154.78 & $0.69(0.54-0.88)$ \\
\hline \multicolumn{4}{|l|}{ Sex } \\
\hline Male & 107.52 & 150.88 & $0.71(0.56-0.91)$ \\
\hline Female & 106.77 & 156.87 & $0.68(0.53-0.87)$ \\
\hline Total & 106.38 & 154.75 & $0.69(0.54-0.88)$ \\
\hline $\begin{array}{l}\text { Sex } \\
\text { (years) }\end{array}$ & & & \\
\hline Male, $<50$ & 73.41 & 102.50 & $0.72(0.53-0.97)$ \\
\hline Male, $\geq 50$ & 137.58 & 197.70 & $0.70(0.56-0.87)$ \\
\hline Female, $<50$ & 54.75 & 76.06 & $0.72(0.51-1.02)$ \\
\hline Female, $\geq 50$ & 180.39 & 272.53 & $0.66(0.55-0.80)$ \\
\hline
\end{tabular}

According to the $\mathrm{P} / \mathrm{l}$ ratio, the appropriate screening intervals were 4 years for men and women below 50 years of age, 5 years for men aged 50 years or above, and 6 years for women aged 50 years or above.

Our proposed method was also useful in assessing the effect of interscreening interval on the efficacy of early detection of type 2 diabetes. In this study, the similar benefit between biennial screening and a 5year screening regimen suggests that the latter may be sufficient for early detection of type 2 diabetes. This can be explained by a long duration as above. However, since the proposed method in this study is not based on a population-based randomized clinical trial (RCT) the evaluation does not take the place of a RCT scientifically, but adds valuable information that may argue for the future implementation of a RCT.

There were two other limitations to this study. First, the return rate from the first to the second screening with complete information on blood sugar was only approximate $32 \%$. Possibly, such a low return rate might lead to a biased result. To check the degree of bias, we performed a series of simulations based on 100, 90, 70, 50 , and $30 \%$ return rates, given $88 \%$ sensitivity and $56 \%$ attendance rate in the first screening. The corresponding estimates for the relative efficacy in reduction of deaths from type 2 diabetes were 33, 33, 32, 31, and $30 \%$, respectively. A return rate of $30 \%$ only led to $9 \%$ reduction of gain from early detection compared to a $100 \%$ return rate. In addition, we calculated the incidence density of type 2 diabetes based on only the 266 subjects who attended three rounds of screening and we compared this estimate with the above estimate of $\lambda_{1}$. However, the difference between the two estimates
TABLE 4

Simulated Results of the Efficacy of Early Detection of Type 2 Diabetes for Biennial Screening Regime versus the Control Group in a Hypothetical Population ( $n=10,000)$ by Sex and Age or Both, Assuming $88 \%$ Sensitivity and 56\% Attendance Rate

\begin{tabular}{|c|c|c|c|}
\hline & \multicolumn{2}{|c|}{$\begin{array}{c}\text { Death from type } 2 \\
\text { diabetes }\end{array}$} & \multirow{2}{*}{$\begin{array}{c}\text { RR screened/ } \\
\text { control } \\
(95 \% \mathrm{Cl})\end{array}$} \\
\hline & Screened & Control & \\
\hline \multicolumn{4}{|l|}{ Age (years) } \\
\hline$<50$ & 57.61 & 87.17 & $0.66(0.47-0.92)$ \\
\hline$\geq 50$ & 144.91 & 231.80 & $0.63(0.51-0.77)$ \\
\hline Total & 99.39 & 154.78 & $0.64(0.50-0.83)$ \\
\hline \multicolumn{4}{|l|}{ Sex } \\
\hline Male & 100.24 & 150.88 & $0.66(0.52-0.86)$ \\
\hline Female & 99.85 & 156.87 & $0.64(0.50-0.82)$ \\
\hline Total & 99.42 & 154.75 & $0.64(0.50-0.83)$ \\
\hline \multicolumn{4}{|c|}{ Sex $\times$ Age (years) } \\
\hline Male, $<50$ & 68.45 & 102.50 & $0.67(0.49-0.91)$ \\
\hline Male, $\geq 50$ & 128.42 & 197.70 & $0.65(0.52-0.81)$ \\
\hline Female, $<50$ & 51.05 & 76.06 & $0.67(0.47-0.96)$ \\
\hline Female, $\geq 50$ & 168.71 & 272.53 & $0.62(0.51-0.75)$ \\
\hline
\end{tabular}

was minor (data not shown), suggesting that the low return rate did not seriously affect estimates.

Second, the $\mathrm{P} / \mathrm{I}$ ratio may be affected by the sensitivity of the screening tool. Thus, our failure to take the sensitivity of the screening tool into account in calculating the $\mathrm{P} / \mathrm{I}$ ratio may have led to further underestimation of the benefit of early detection of type 2 diabetes. To check this concern, a series of simulations assuming $100,95,90,85$, and $80 \%$ sensitivity given a $56 \%$ re sponse rate was performed to examine how sensitivity would affect the efficacy of early detection in preventing death from type 2 diabetes. The similarities in the relative risks calculated $(0.67,0.68,0.69,0.69$, and 0.70 , respectively) suggest that ignoring the sensitivity may have only a minor effect on the estimated efficacy of early detection.

In conclusion, a $31 \%$ mortality reduction from type 2 diabetes due to early detection was demonstrated in this study based on a Markov method incorporating the relationships between prevalence, incidence, and mortality. This suggests that early detection of type 2 diabetes in devel oping countries with a high prevalence of type 2 diabetes should be implemented.

\section{APPENDIX A}

The algebra of estimating $\lambda_{1}$ and $\lambda_{2}$ is

$\lambda_{1}$ (Normal $\rightarrow$ Asymptomatic Type 2 Diabetes)

No. of asymptomatic type 2 diabetes in second screen Person years between first and second screen 
Average duration from asymptomatic type 2

diabetes to symptomatic type 2 diabetes

$$
\begin{aligned}
& \begin{array}{c}
\text { Prevalence of Asymptomatic Type 2 Diabetes } \\
\text { (No. of asymptomatic type 2 diabetes }
\end{array} \\
= & \frac{\lambda_{1}}{\text { in first screen/ number of attendants) }} \\
= & \frac{1}{\lambda_{2}}
\end{aligned}
$$

\section{APPENDIX B}

Let the duration between the asymptomatic phase and symptomatic phase and the survival time after the symptomatic phase be denoted as $t$ and $x$, respectively. The total duration from the asymptomatic phase to death is $z(t+x)$. Parameters corresponding to $t$ and $x$ in this study were denoted as $\lambda_{2}$ and $\lambda_{3}$. Walter and Stitt showed that if $x$ can beassumed to have an exponential distribution, the corresponding parameter, $\lambda_{3}$, can be estimated in light of the probability of death during each life-table interval. For the interval $\left(z_{i}, z_{i+1}\right)$, this probability is

$$
\begin{aligned}
& P\left(z_{i}, z_{i+1}\right)= \\
& \frac{\lambda_{3}\left[\exp \left(-\lambda_{2} z_{i+1}\right)-\exp \left(-\lambda_{2} z_{i}\right)\right]-\lambda_{2}\left[\exp \left(-\lambda_{3} z_{i+1}\right)-\exp \left(-\lambda_{3} z_{i}\right)\right]}{\lambda_{2} \exp \left(-\lambda_{3} z_{i}\right)-\lambda_{3} \exp \left(-\lambda_{2} z_{i}\right)}
\end{aligned}
$$

One can multiply the numbers of persons $n_{i}$ at risk by the above probability to obtain expected death and let

$$
\text { Observed death }=\text { Expected death }(=\mathrm{P} \times \mathrm{n})+\text { Error. }
$$

Given a value of 0.0999 (1/10.01) for $\lambda_{2}$ (see Table 2), the application of this equation to the cumulative survival data on 117 subjects (see below) yield 1.1\% for $\lambda_{3}$. A nonlinear regression using the SAS procedure NLIN was used to estimate $\lambda_{3}$. The survival data in life-table form and estimating program are shown in the following:

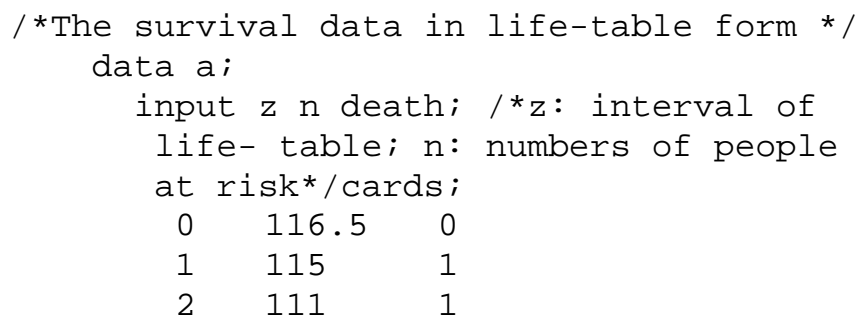

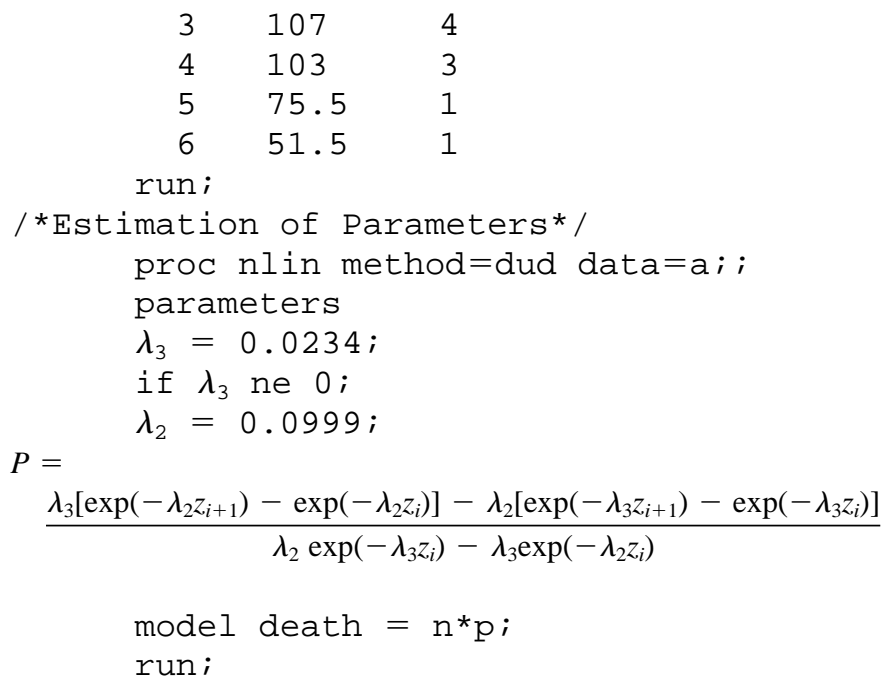

\section{REFERENCES}

1. Harris MI. Kelly West Lecture: Undiagnosed NIDDM, clinical, and public health issues. Diabetes Care 1993;16:642-52.

2. Singer DE, Samet JH, Coley CM, Nathan DM. Screening for diabetes mellitus. Ann Intern Med 1988;109:639-49.

3. Singer DE, Nathan DM. Screening for diabetes mellitus: Guide to clinical preventive services. U.S. DHHS, 1989.

4. Knowler WC. Screening for NIDDM: Opportunities for detection, treatment, and prevention. Diabetes Care 1994;17:445-449.

5. Stewart-Brown S, Farmer A. Screening could seriously damage your health. BMJ 1997;314:533.

6. American Diabetes Association. Screening for type 2 diabetes. Diabetes Care 1998;21:S20-2.

7. Harris MI, Klein R, Welborn TA, Knuiman MW. Onset of NIDDM occurs at least 4-7 years before clinical diagnosis. Diabetes Care 1992;15:815-9.

8. CDC Diabetes Cost-Effectiveness Study Group. The cost-effectiveness of screening for type 2 diabetes. JAMA 1998;280: 1757-63.

9. Freeman J , Hutchison GB. Prevalence, incidence and duration. Am J Epidemiol 1980;112:707-23.

10. Chou P, Chen HH, Hsiao KJ . Community-based epidemiological study on diabetes in Pu-Li, Taiwan. Diabetes Care 1992;15:81- 9.

11. Kuo HS, Chang HJ , Chou P, Teng LL, Chen TH. A Markov chain model to assess the efficacy of screening for non-insulin dependent diabetes mellitus (NIDDM). Int J Epidemiol 1999;28: 233-40.

12. Rothman KJ , Greenland S. Modern epidemiology. Philadel phia: Lippincott-Raven, 1998.

13. Walter SD, Stitt LW. Evaluation the survival of cancer cases detected by screening. Stat Med 1987;6:885-900.

14. Etzioni RD, Connor RJ , Prorok PC, Self SG. Design and analysis of cancer screening trials. Stat Methods Med Res 1995;4:3-17.

15. J arrett RJ . Duration of non-insulin dependent diabetes and development of retinopathy: Analysis of possible risk factors. Diabetic Med 1986;3:261-3. 